\title{
A review of genus-group names in Diptera (Insecta) that J.C. Fabricius "borrowed" from other dipterists and proposed as new in his systematic works from 1775 to 1805
}

Michelsen, Verner; O'Hara, James E.

Published in:

Zootaxa

DOI:

10.11646/zootaxa.3873.1.6

Publication date:

2014

Document version

Publisher's PDF, also known as Version of record

Document license:

CC BY

Citation for published version (APA):

Michelsen, V., \& O'Hara, J. E. (2014). A review of genus-group names in Diptera (Insecta) that J.C. Fabricius "borrowed" from other dipterists and proposed as new in his systematic works from 1775 to 1805. Zootaxa, 3873(1), 73-81. https://doi.org/10.11646/zootaxa.3873.1.6 
http://dx.doi.org/10.11646/zootaxa.3873.1.6

http://zoobank.org/urn:Isid:zoobank.org:pub:66DDFEA9-E1CE-43C1-B09F-FE8504898312

\title{
A review of genus-group names in Diptera (Insecta) that J.C. Fabricius "borrowed" from other dipterists and proposed as new in his systematic works from 1775 to 1805
}

\author{
VERNER MICHELSEN ${ }^{1} \&$ JAMES E. O'HARA ${ }^{2}$ \\ ${ }^{\prime}$ Zoological Museum, Natural History Museum of Denmark, University of Copenhagen, Denmark. E-mail: vmichelsen@snm.ku.dk \\ ${ }^{2}$ Canadian National Collection of Insects, Agriculture and Agri-Food Canada, 960 Carling Avenue, Ottawa, Ontario, Canada, K1A \\ 0C6.E-mail: james.ohara@agr.gc.ca
}

\begin{abstract}
It is shown that a total of eight pre-existing genus-group names in Diptera were "borrowed" and deliberately given new identities in the systematic works of J.C. Fabricius: Bibio Fabricius, 1775, Ceria Fabricius, 1794, Hirtea Fabricius, 1798, Mulio Fabricius, 1798, Scatophaga Fabricius, 1805, Sicus Fabricius, 1798, Thereva Fabricius, 1798 and Voluccella Fabricius, 1794. These names are reviewed from the standpoint that they are nomenclaturally available as intentional homonymous proposals of names for new genus-group taxa. New type-species designations are made for Bibio Fabricius, Mulio Fabricius, and Scatophaga Fabricius. Bibio Fabricius, 1775 is recognized as a senior synonym of Thereva Latreille, 1797, syn. n., but is invalid as it is a junior homonym of Bibio Geoffroy, 1762. Scatophaga Fabricius, 1805 is recognized as a junior synonym of Psila Meigen, 1803, syn. n. The nominal species Musca suilla Fabricius, 1794 has been misinterpreted as a species of Scathophaga Meigen, 1803 by subsequent authors. Scathophaga spurca Meigen, 1826 is revived as the valid name for Scathophaga suilla auct. nec (Fabricius, 1794), stat. rev. A lectotype is designated for Musca suilla Fabricius and it is shown to belong to the scathophagid Norellisoma spinimanum (Fallén, 1819), syn. n. In order to maintain stability of nomenclature and prevailing usage, reversal of precedence is invoked to declare Cordylura spinimana Fallén, 1819 as a nomen protectum and Musca suilla Fabricius, 1794 as a nomen oblitum.
\end{abstract}

Key words: Nomenclature, taxonomy, Bibionidae, Bombyliidae, Psilidae, Scathophagidae, Syrphidae, Tachinidae, Therevidae, Xylophagidae

\section{Introduction}

Johann Christian Fabricius (1745-1808), acknowledged for his pioneering early post-Linnaean classification of insects, had the strange habit of occasionally proposing new genera in Diptera (and probably other insects) with names already published by other authors for entirely different groups of Diptera. He did so openly and intentionally, as he often cited the earlier usage of such names under the appropriate genus in his own classification. Even if this habit appears strange and confusing today, we should keep in mind that Fabricius worked at a time without any constraints, in terms of Code regulations, such as the Principles of Priority and Homonymy. Opinions have been and still are dividing dipterists, whether these names should be formally dismissed as misidentifications (e.g., Holston et al. 2003) or treated as separate proposals as was clearly intended by Fabricius himself (e.g., Michelsen 2004). As these names satisfy the criteria of availability, i.e., the provisions of Articles 10 to 20 in the International Code of Zoological Nomenclature (International Commission on Zoological Nomenclature 1999), hereafter simply the Code, there is no formal hindrance to treating them as proper genus-group names with their own authorship and date.

It is widely accepted that unintentional homonymous proposals of names for new taxa make such names nomenclaturally available with their own authorship and date. Fabricius's generic names dealt with in the present paper may be categorized as intentional homonymous proposals of names for new genus-group taxa. Michelsen (2004) gave several reasons for preferably treating these names as nomenclaturally available with their own 
authorship and date. Firstly, in the spirit of the Code (p. xix), one should refrain from 'infringing upon taxonomic judgment, which must not be made subject to regulation or restraint.' In other words, one should preferably not set aside Fabricius's clear intentions by dismissal of his alternative usages of certain genus-group names. Secondly, because of the Principle of Homonymy, this is the safest and simplest way to promote nomenclatural stability. Finally, in treating Fabricius's usage of these names as nominal taxa in their own right rather than misidentifications we do not obscure the intentions and results of the first major post-Linnaean proposal of a generic classification of Diptera.

The idea that Fabricius's altered usages of generic names in Diptera are preferably to be treated as separate proposals rather than misidentifications is implicit in several decisions of the International Commission on Zoological Nomenclature (1957: 88; 1997: 133; 2006: 72), where some of these names are categorized as homonymous proposals. Commission member Dr M. Alonzo-Zarazaga stated (2006: 73) that ' $\ldots$ the problem of Fabrician altered usages of generic names proposed by other authors under the principle of his authority (the 'Prince of Entomology') should be addressed by the Commission once and for all. Considering them available junior homonyms could be the best procedure, in my opinion'.

The alternative proposals of genus-group names in Diptera found in the systematic works of Fabricius are treated alphabetically in the following catalogue. It is further documented that the species-group name Musca suilla Fabricius, 1794 (Scathophagidae) has been misinterpreted by all subsequent authors. The nomenclatural implications are settled by invoking reversal of precedence for the names Musca suilla Fabricius, 1794 and Cordylura spinimana Fallén, 1819.

\section{Catalogue}

Bibio Fabricius, 1775: [31], 756.

Type species: Musca plebeja Linnaeus, 1758 (the 4th of 14 originally included species), by present designation. Junior homonym of Bibio Geoffroy, 1762. Objective synonym of Thereva Latreille, 1797 (see below), syn. n. (Therevidae).

Remarks. The name Bibio Geoffroy, 1762, originally proposed mainly for species of Bibionidae, was cited under Tipula hortulana Linnaeus by Fabricius (1775: 754, 1794: 248). In the same work Fabricius (1775) made his own proposal of the name Bibio for 14 species belonging to the families Bombyliidae (8), Therevidae (4), Mydidae (1) and Stratiomyidae (1). Fabricius (1805) later refined his concept of Bibio to consist of 10 Therevidae and 1 species each of the families Athericidae, Phoridae and Syrphidae. Fabricius's usage of Bibio for therevid flies became widely accepted in the pre-1815 literature (J.W. Meigen, C.F. Fallén, etc.), but was later replaced by the name Thereva Latreille, 1797. The type species of Thereva Latreille, 1797 was designated by the International Commission on Zoological Nomenclature (2006: 72) as Musca plebeja Linnaeus, 1758 under their Plenary Powers. The present fixation of a type species for Bibio Fabricius, 1775 places at long last this name into formal (and objective) synonymy with Thereva Latreille. Incidentally, the International Commission on Zoological Nomenclature (1957: 88) placed Bibio Fabricius, 1775 on the Official Index of Rejected and Invalid Generic Names in Zoology (Name No. 841).

Ceria Fabricius, 1794: 277.

Type species: Ceria clavicornis Weber, 1795 [= Musca conopsoides Linnaeus, 1758], by subsequent monotypy (Weber 1795). Junior homonym of Ceria Scopoli, 1763. Replaced by Ceriana Rafinesque, 1815, nomen novum for Ceria Fabricius, 1794 (Syrphidae).

Remarks. The name Ceria Scopoli, 1763 was originally proposed for two species of Scatopsidae. Fabricius (1794) proposed the name Ceria for a species of Syrphidae and his usage of the name became widely accepted in pre-1902 literature (P.A. Latreille, J.W. Meigen, J.W. Zetterstedt, G.H. Verrall, etc.).

A description of the only included species was given by Fabricius (1794), but inadvertently the specific name 
[clavicornis] was omitted. It first appeared in an index to the four volumes (1792-1794) of Fabricius's Entomologia systematica emendata et aucta prepared by Weber (1795). Accordingly, the authorship of Ceria clavicornis is correctly attributed to Weber (1795) rather than Fabricius (1794). This interpretation of type fixation of Ceria Fabricius, 1794 is the same as that of Sabrosky (1999: 79) except that authorship of Ceria clavicornis was attributed in that work to Fabricius, 1795 not Weber, 1795.

\section{Hirtea Fabricius, 1798: 547, 551.}

Type species: Tipula marci Linnaeus, 1758 (cited by Fabricius in synonymy with Tipula hortulana Linnaeus, 1758, the 2nd of 13 originally included species), by subsequent designation of Zetterstedt (1850: 3368). Junior homonym of Hirtea Scopoli, 1763. Junior subjective synonym of Bibio Geoffroy, 1762 (type species: Tipula hortulana Linnaeus, 1758) (Bibionidae).

Remarks. Hirtea Scopoli, 1763 was originally proposed for a species of the family Stratiomyidae. Fabricius (1798) made his own proposal of the name Hirtea for 13 species belonging to the families Bibionidae (8), Sciaridae (2), Cecidomyiidae (1), Scatopsidae (1) and Therevidae (1). In his final classification, Fabricius (1805) included in Hirtea 14 Bibionidae, 1 Sciaridae and 1 Therevidae. Fabricius's usage of the name Hirtea for bibionid flies became widely accepted in the pre-1850 literature (J.W. Meigen, G.W.F. Panzer, J.W. Zetterstedt, etc.), but was gradually replaced by the older name Bibio Geoffroy, 1762. Incidentally, the International Commission on Zoological Nomenclature (1957: 88) placed Hirtea Fabricius, 1798 on the Official Index of Rejected and Invalid Generic Names in Zoology (Name No. 840).

\section{Mulio Fabricius, 1798: 548, 557.}

Type species: Musca bicincta Linnaeus, 1758 (the 1st of nine originally included species), by present designation. Junior homonym of Mulio Latreille, 1797. Senior but invalid objective synonym of Chrysotoxum Meigen, 1803 (type species: Musca bicincta Linnaeus, 1758) (Syrphidae).

Remarks. The first usage of the name Mulio by Latreille (1797) was for species of the family Bombyliidae. Fabricius (1798) proposed Mulio for nine species belonging to the families Syrphidae (7), Psilidae (1) and Sciomyzidae (1), but subsequently (1805) exclusively for 12 species of Syrphidae. Fabricius's usage of Mulio received limited acceptance in the early literature (e.g., by C.F. Fallén), probably because Meigen (1803) transferred species recognized in Mulio by Fabricius (1798) to two new genera of Syrphidae (Microdon Meigen, Chrysotoxum) and one new genus of Psilidae (Loxocera Meigen).

\section{Scatophaga Fabricius, 1805: x, 203.}

Type species: Musca fimetaria Linnaeus, 1761 (the 5th of 31 originally included species), by present designation. Junior objective synonym of Psila Meigen, 1803 (type species: Musca fimetaria Linnaeus, 1761), syn. n. (Psilidae).

Remarks. Scathophaga Meigen, 1803, originally proposed for dung flies ("Musca merdaria etc. Fabricius") of the family Scathophagidae, was cited by Fabricius (1805: 306, misspelled as Scatophaga) under Musca merdaria Fabricius, 1794 (= Musca stercoraria Linnaeus, 1758). Other species of the current genus Scathophaga Meigen (e.g., scybalaria Linnaeus, 1758 and lutaria Fabricius, 1794) were also consistently classified in Musca Linnaeus, 1758 by Fabricius (1805). However, Fabricius (1805: 203-210) proposed a different usage of the name Scatophaga for 31 species of mostly testaceous acalyptrate flies with a short, porrect antennal postpedicel. Most of the included species belong to the families Sciomyzidae, Lauxaniidae and Ulidiidae. Species of Scathophaga Meigen are different in having antennae with a longer, deflexed postpedicel. Only a single species (Musca suilla Fabricius, 1794) among the 31 species originally included in Scatophaga Fabricius belongs to the Scathophagidae. The identity of that nominal species is treated below.

The different usage of the name Scatophaga introduced by Fabricius (1805), which embraces a poorly defined 
assemblage of mostly acalyptrate flies, has consistently been overlooked (or ignored?) by dipterists up to the present. Adding to the confusion, Meigen (1826) adopted Fabricius's spelling "Scatophaga" for his own genus of dung flies without, of course, adopting Fabricius's usage of the name. This should be categorized as an "incorrect subsequent spelling" of Scathophaga Meigen, even though it may well have been done deliberately.

The present fixation of a type species refers Scatophaga Fabricius to the Psilidae. Note that Scatophaga Fabricius, 1805 and Scathophaga Meigen, 1803 are not homonyms according to the Code Article 56.2 (one letter difference).

\section{Sicus Fabricius, 1798: 547, 554.}

Type species: Musca ferruginea Scopoli, 1763, as a consequence of a ruling by the International Commission on Zoological Nomenclature (1997: 133). By the same ruling, Sicus Fabricius, 1798 was placed on the Official Index of Rejected and Invalid Generic Names in Zoology and declared a junior objective synonym of Coenomyia Latreille, 1797 (Xylophagidae). Junior homonym of Sicus Scopoli, 1763 and Sicus Latreille, 1797.

Remarks. The first usage of the name Sicus was by Scopoli (1763) for species of Conopidae, the second usage was by Latreille (1797) for a species of Hybotidae, and the third usage was by Fabricius (1798) for five nominal species of Xylophagidae. These five nominal species of Sicus Fabricius are all, with varying confidence, regarded as junior synonyms of one variable species, Coenomyia ferruginea (Scopoli, 1763). Although one of Fabricius's species was named Sicus ferruginea and has subsequently been established as a synonym of Musca ferruginea Scopoli, 1763, there was no indication by Fabricius that his ferruginea was used in the sense of ferruginea Scopoli. We contend that the Fabricius name was a separate proposal and should have been interpreted by subsequent authors as ferruginea Fabricius, 1798, not as ferruginea Scopoli, 1763. Under such an interpretation, Sabrosky (1961: 228) could not have designated Musca ferruginea Scopoli as the type species of Sicus Fabricius. We will not elaborate on the nomenclatural ramifications this would have had on the type species of Coenomyia Latreille, 1797 and Sicus Fabricius, 1798 because the International Commission on Zoological Nomenclature (1997: 133) ruled that Sicus Fabricius, 1798 is a junior objective synonym of Coenomyia Latreille, 1797, thereby effectively upholding the type species of Sicus Fabricius as Musca ferruginea Scopoli, 1763. The name Sicus Fabricius, 1798 was placed on the Official Index of Rejected and Invalid Generic Names in Zoology by the same ruling and according to Code Article 80.7.1: "A work, name or nomenclatural act entered in an Official Index has the status attributed to it in the relevant ruling(s)."

\section{Thereva Fabricius, 1798: 548, 560.}

Type species: Conops subcoleoptratus Linnaeus, 1767 (the 1st of six included species), by designation of Herting (1984: 168). Junior homonym of Thereva Latreille, 1797. Senior but invalid objective synonym of Phasia Latreille, 1804 (type species: Conops subcoleoptratus Linnaeus, 1767) (Tachinidae). The International Commission on Zoological Nomenclature (2006) placed the name Thereva Fabricius, 1798 on the Official Index of Rejected and Invalid Generic Names in Zoology following an application by Holston et al. (2003).

Remarks. The first usage of the name Thereva by Latreille (1797) was for species of Therevidae and thus equals the earlier usage of Bibio by Fabricius (1775). Fabricius (1798) first proposed the name Thereva for six species of Tachinidae, and subsequently (Fabricius, 1805) for 13 Tachinidae and one Syrphidae. Fabricius's usage of Thereva for species of phasiine Tachinidae became widely accepted in the pre-1820 literature (J.W. Meigen, G.W.F. Panzer, C.F. Fallén, etc.), but his name was replaced later by Phasia Latreille, 1804.

\section{Voluccella Fabricius, 1794: 412.}

Type species: Voluccella florea Fabricius, 1794 (the 1st of three originally included species), automatic as the result of Latreille's (1810) designation of Voluccella florea Fabricius as type species for Usia Latreille, 1802, an unnecessary new replacement name for Voluccella Fabricius, 1794. Voluccella Fabricius, 1794 was placed on the 
Official Index of Rejected and Invalid Generic Names in Zoology (Name No. 844) by the International Commission on Zoological Nomenclature (1957: 88) and is therefore a senior but invalid synonym of Usia Latreille (Bombyliidae).

Remarks. The name Volucella Geoffroy, 1762, as originally proposed for species of Syrphidae, was cited under Musca pellucens Linnaeus, 1758 by Fabricius (1775: 773, misspelled as Voluccella; 1781: 435, as Voluccella), and under Syrphus pellucens (Linnaeus, 1758) by Fabricius (1794: 279, as Volucella; 1805: 224, as Voluccella).

Fabricius (1794: 412) deliberately proposed a different usage of the name Voluccella for three species of the family Bombyliidae, and this usage qualifies as a new available name. Two original spellings of the name were given in Fabricius (1794): Voluccella (p. 412) and Volvicella (p. [5] of the unnumbered index). Acting as First Reviser, Fabricius (1805) selected Voluccella as the correct original spelling (Code Article 24.2.4). Fabricius (1805: 114-116) included six species of the Bombyliidae in his Voluccella. Meigen (1804) initially adopted the usage of Voluccella proposed by Fabricius, but the name was subsequently replaced by Usia Latreille.

Volucella Geoffroy and Voluccella Fabricius are not homonyms because the names differ by one letter (Code Article 56.2). Evenhuis \& Greathead (2003: 10-11) understood this and believed therefore that the widely used generic name Usia Latreille, 1802 in Bombyliidae, originally proposed as a replacement name for Voluccella Fabricius, 1794, was threatened as a junior synonym. These authors were aware that Voluccella Fabricius was invalid as the result of a ruling by the International Commission on Zoological Nomenclature (1957: 88) (see Evenhuis 1991: 77) but were concerned that this ruling could be challenged and potentially overturned (as allowed under Code Article 80.4) because it was based on the misinterpretation of Voluccella as a misspelling of Volucella Geoffroy (N. Evenhuis, pers. comm.). To permanently fix the priority of Usia Latreille, 1802 over Voluccella Fabricius, 1794, Evenhuis \& Greathead (2003) declared the former as a nomen protectum and the latter as a nomen oblitum.

\section{The identity of Musca suilla Fabricius, 1794}

\section{Musca suilla Fabricius, 1794: 343.}

Type material (Figs. 1-3). Fabricius (1794) stated only the origin 'in Germaniae' [ = in Germany], and collector 'Smidt' [= A. L. Smidt?] of the type material of Musca suilla. Accordingly, the only specimen (1 $)$ found in Coll. Fabricius [= 'Kiel' of Zimsen 1964: 475] of the Natural History Museum of Denmark, Copenhagen, may be regarded as a syntype. It is here designated as lectotype and labelled as such, in order to fix the identity of the name suilla. Only the wings, posterior part of the mesonotum and distal part of the coxa + trochanter + basal part of femur of the left hind leg remain of the lectotype, attached to a short pin with a Fabrician label reading 'suilla'.

Identity. Musca suilla Fabricius, 1794 is not a species of Scathophaga Meigen, 1803 as first surmised by Fallén's (1819) placement of the species in his equivalent genus Scatomyza Fallén, 1810. Accordingly, Musca suilla is not a senior synonym of Scathophaga spurca Meigen, 1826 (published as "Scatophaga" spurca) as first proposed by Becker (1894: 167) and accepted by subsequent authors (e.g., Thompson \& Pont 1994). The colour, the pale setae on the hind leg fragment, the scutellum with only one pair of strong setae (two pairs in relevant species of Scathophaga!), the wing venation including a costal vein with humeral and subcostal breaks and uniform, fine setulae leave no doubt that the remains of the lectotype (Figs. 1, 2) belong to a common European scathophagid originally described as Cordylura spinimana Fallén, 1819 and currently known as Norellisoma spinimanum (Fallén), syn. n. The presence of a black seta among the pale setae on the distal part of the hind coxa further indicates that the lectotype remains belong to a female.

The nominal species Musca suilla Fabricius, 1794 has not previously been synonymized with Norellisoma spinimanum (Fallén, 1819), but has since 1894 consistently been misinterpreted as a species of Scathophaga Meigen. The junior synonym Cordylura spinimana Fallén, 1819 has been used as valid as either Norellia (Norellisoma) spinimana (Fallén) or Norellisoma spinimanum (Fallén) in more than 25 works by at least 10 authors in the last 50 years and encompassing a span of not less than 10 years as documented in Appendix 1. We hereby invoke, in the interests of nomenclatural stability, reversal of precedence (Code Article 23.9), and declare Musca suilla Fabricius, 1794 as a nomen oblitum and Cordylura spinimana Fallén, 1819 as a nomen protectum. 
As discussed in the above catalogue, Fabricius (1805) proposed the name Scatophaga for species of Sciomyzidae and similar flies with a short and porrect antennal postpedicel. Meigen (1803) proposed the name Scathophaga [misspelled later by Meigen (1826) as Scatophaga], for scathophagid dung flies: i.e., hairy species with a longer and deflexed postpedicel. Fabricius consistently classified species of scathophagid dung flies in the genus Musca Linnaeus.
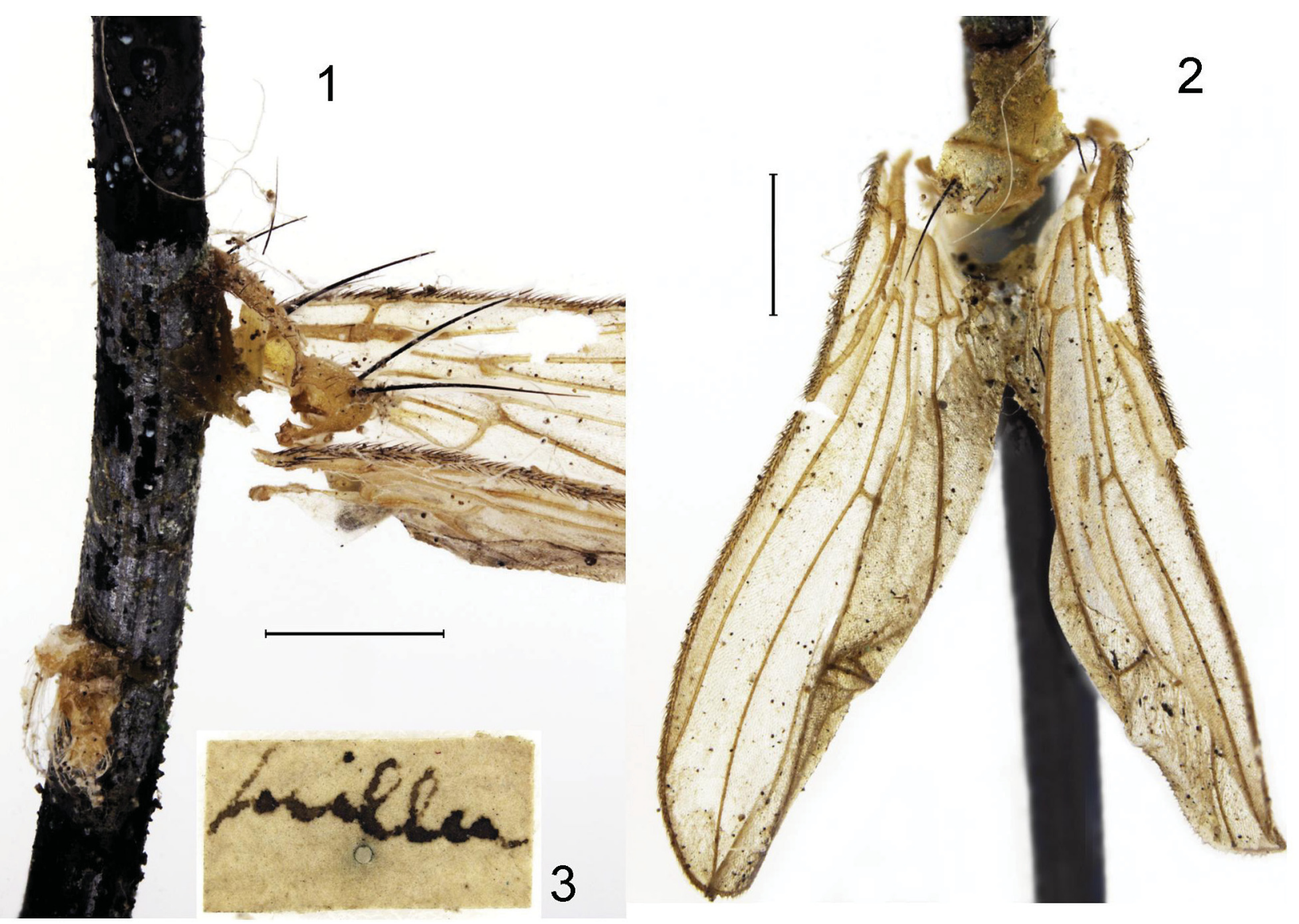

FIGURES 1-3. Musca suilla Fabricius, 1794: lectotype $q$. 1. Remains of mesonotum, left distal part of coxa + trochanter + basal part of femur and basal half of wings in lateral view. 2. Remains of mesonotum and wings in dorsal view. 3. Original label in Fabricius's hand reading "suilla". Scale bars $(1,2)=1 \mathrm{~mm}$.

\title{
The nomenclatural summary of this situation is as follows:
}

\author{
Family SCATHOPHAGIDAE
}

Genus Norellisoma Wahlgren, 1917

Norellisoma spinimanum (Fallén, 1819)

Musca suilla Fabricius, 1794: 343, nomen oblitum, syn. n.

Scatophaga suilla (Fabricius); Fabricius (1805: 206).

Cordylura spinimana Fallén, 1819: 7, nomen protectum.

Genus Scathophaga Meigen, 1803

Scathophaga spurca Meigen, 1826 (Scatophaga), stat. rev.

Scatomyza suilla (Fabricius); Fallén (1819: 5). Misidentification. 
Scatophaga spurca Meigen, 1826: 250.

Scatophaga suilla (Fabricius); Becker (1894: 167). Misidentification.

\section{Acknowledgements}

It is a pleasure to thank Neal Evenhuis (J. Linsley Gressitt Center for Entomological Research, Bishop Museum, Honolulu) for his encouragement and helpful advice on various aspects of this paper. We also thank Thomas Pape (Natural History Museum of Denmark, Copenhagen) and Chris Thompson (formerly Systematic Entomology Laboratory, USDA, Washington, DC) for sharing their views on intricate nomenclatural issues and for valuable information. Finally our thanks go to the reviewers Knut Rognes (Oslo) and an anonymous reviewer for their constructive criticism and suggestions.

\section{References}

Becker, T. (1894) Dipterologische Studien. I. Scatomyzidae. Berliner Entomologische Zeitschrift, 39, 77-196, pls. 4-9.

Evenhuis, N.L. (1991) World catalog of genus-group names of bee flies (Diptera: Bombyliidae). Bishop Museum Bulletins in Entomology, 5, vii + 105 pp.

Evenhuis, N.L. \& Greathead, D.J. (2003) World catalog of bee flies (Diptera: Bombyliidae): Corrigenda and addenda. Zootaxa, $300,1-64$.

Fabricius, J.C. (1775) Systema entomologiae, sistens insectorum classes, ordines, genera, species, adiectis synonymis, locis, descriptionibus, observationibus. Kortii, Flensbvrgi et Lipsiae [= Flensburg and Leipzig], [30] + 832 pp. http://dx.doi.org/10.5962/bhl.title.36510

Fabricius, J.C. (1781) Species insectorum exhibentes eorum differentias specificas, synonyma auctorum, loca natalia, metamorphosin adiectis observationibus, descriptionibus. Tom. II. C.E. Bohnii, Hamburgi et Kilonii [= Hamburg and Kiel], 517 pp.

Fabricius, J.C. (1794) Entomologia systematica emendata et aucta. Secundum classes, ordines, genera, species adjectis synonimis, locis, observationibus, descriptionibus. Tom. IV. C.G. Proft, Fil. et Soc., Hafniae [= Copenhagen], [6] + 472 + [5] pp.

Fabricius, J.C. (1798) Supplementum entomologiae systematicae. Proft et Storch, Hafniae [= Copenhagen], [2] + 572 pp.

Fabricius, J.C. (1805) Systema antliatorum secundum ordines, genera, species adiectis synonymis, locis, observationibus, descriptionibus. C. Reichard, Brunsvigae [= Brunswick $]$, xiv $+15-372+[1$ (errata) $]+30$ pp.

Fallén, C.F. (1819) Scatomyzides sveciae. Berlingianis, Lundae [= Lund], 10 pp.

Herting, B. (1984) Catalogue of Palearctic Tachinidae (Diptera). Stuttgarter Beiträge zur Naturkunde. Serie A (Biologie), 369, $1-228$.

Holston, K.C., Irwin, M.E. \& Thompson, F.C. (2003) Thereva Latreille, 1797 and Phasia Latreille, 1804 (Insecta, Diptera): proposed conservation of usage by designation of Musca plebeja Linnaeus, 1758 as the type species of Thereva. Bulletin of Zoological Nomenclature, 60, 198-202.

International Commission on Zoological Nomenclature (1957) Opinion 441. Validation under the Plenary Powers of the names for five genera in the Order Diptera (Class Insecta) published in 1762 by Geoffroy (E.L.) in the work entitled "Histoire abrégée des insectes qui se trouvent aux environs de Paris." (Opinion supplementary to Opinion 228.) Opinions and Declarations Rendered by the International Commission of Zoological Nomenclature, 15, 83-120.

International Commission on Zoological Nomenclature (1997) Opinion 1870. Sicus Scopoli, 1763 and Myopa Fabricius, 1775 (Insecta, Diptera): conserved by the designation of Conops ferrugineus Linnaeus, 1761 and C. buccatus Linnaeus, 1758 as the respective type species; and Coenomyia Latreille, 1796 placed on the Official List. Bulletin of Zoological Nomenclature, 54, 133-135.

International Commission on Zoological Nomenclature (1999) International Code of Zoological Nomenclature. Fourth Edition. International Trust for Zoological Nomenclature, London. xxix $+306 \mathrm{pp}$.

International Commission on Zoological Nomenclature (2006) Opinion 2142 (Case 3251). Thereva Latreille, 1797 and Phasia Latreille, 1804 (Insecta, Diptera): usage conserved by the designation of Musca plebeja Linnaeus, 1758 as the type species of Thereva. Bulletin of Zoological Nomenclature, 63, 72-73.

Latreille, P.A. (1797) Précis des caractères génériques des insectes, disposés dans un ordre naturel. Prévôt, Paris \& F. Bourdeaux, Brive, xiv $+201+$ [7] pp., 1 map.

Latreille, P.A. (1810) Considérations générales sur l'ordre naturel des animaux composant les classes des crustacés, des arachnides, et des insectes; avec un tableau méthodique de leurs genres, disposés en familles. F. Schoell, Paris, 444 pp.

Meigen, J.W. (1803) Versuch einer neuen Gattungs-Eintheilung der europäischen zweiflügligen Insekten. Magazin für Insektenkunde, 2, 259-281.

Meigen, J.W. (1804) Klassifikazion und Beschreibung der europäischen zweiflügeligen Insekten. (Diptera Linn.). Erster Band. 
K. Reichard, Braunschweig [= Brunswick]. Abt. 1, xxviii + 1-152, pls. 1-8; Abt. 2, vi + 153-314, pls. 9-15.

Meigen, J.W. (1826) Systematische Beschreibung der bekannten europäischen zweiflügeligen Insekten. Fünfter Theil. Schulz, Hamm, xii +412 pp, pls. 42-54.

Michelsen, V. (2004) Comments on the proposed conservation of usage of Thereva Latreille, 1797 (Insecta, Diptera) by designation of Musca plebeja Linnaeus, 1758 as the type species of Thereva. Bulletin of Zoological Nomenclature, 61, 254-255.

Sabrosky, C.W. (1961) Comments on the report on the names published by Meigen, 1800. Bulletin of Zoological Nomenclature, 19, 227-229.

Sabrosky, C.W. (1999) Family-group names in Diptera. An annotated catalog. Myia, 10, 1-360.

Scopoli, J.A. (1763) Entomologia Carniolica exhibens insecta Carnioliae indigena et distributa in ordines, genera, species, varietates. Methodo Linnaeana. I.T. Trattner, Vindobonae [= Vienna], [30] $+420+[1] \mathrm{pp}$.

Thompson, F.C. \& Pont, A.C. (1994) Systematic database of Musca names (Diptera). A catalog of the names associated with the genus-group name Musca Linnaeus, with information on their classification, distribution, and documentation. Theses zoologicae, 20 (1993), pp. 1-219 [+ 1-2].

Weber, F. (1795) Nomenclator entomologicus. C. E. Bohn, Chilonii et Hamburgii [= Kiel \& Hamburg], 171 pp.

Zetterstedt, J.W. (1850) Diptera scandinaviae. Disposita et descripta. Tom. 9. Officina Lundbergiana, Lundae [= Lund], pp. 3367-3710.

Zimsen, E. (1964) The type material of I.C. Fabricius. Munksgaard, Copenhagen, 656 pp.

\section{APPENDIX I}

List of publications treating Cordylura spinimana Fallén, 1819 as a valid species-group name

Barták, M. \& Kubík, Š. (2006) Scathophagidae, pp. 362-365. In: Barták, M. \& Kubík, ک̌. (eds.), Diptera of the Podyjí National Park and its environs. Česká zemědělská univerzita v Praze: PowerPrint, Praha 6 - Suchdol.

Barták, M. \& Roháček, J. (2009) Scathophagidae, pp. 285-288. In: Roháček, J. \& Ševčik, J. (eds.), Diptera of the Pol'ana Protected Landscape Area - Biosphere Reserve (Central Slovakia). SNC SR, Administration of the PLA - BR Polana, Zvolen.

Chandler, P. (1998) Checklists of insects of the British Isles (New series) Part 1: Diptera. Handbooks for the Identification of British Insects, 12, $\mathrm{xx}+234 \mathrm{pp}$.

Delyné Draskovits, Á. (1981) 76. család: Scathophagidae - Töviseslegyek. Fauna hungarica, 145 (XV. kötet, Diptera II, 10. füzete), 1-52. Akadémia Nyomda, Budapest. [In Hungarian.]

Disney, R.H.L. (1976) The pre-adult stages of Norellisoma spinimanum (Fallén) (Dipt., Cordyluridae) and a parasitoid (Hym., Pteromalidae) of the same. Entomologist's Gazette, 27, 263-267.

Draber-Mońko, A. (1991) Scathophagidae. In: Razowski, J. (ed.), Checklist of animals of Poland, 2, 231-233. Ossolineum Press, Wrocław.

Gorodkov, K.B. (1970) [Family Scatophagidae (Cordyluridae, Scatomyzidae, Scopeumatidae)]. In: Bei-Bienko, G.Y. (ed.), Opredelitel' nasekomykh Evropeiskoi chasti SSSR, 5, Diptera, Siphonaptera 2, 440-458. [In Russian.]

Gorodkov, K.B. (1986) Family Scathophagidae. In: Soós, Á. \& Papp, L. (eds.), Catalogue of Palaearctic Diptera, 11, $11-41$. Hungarian Natural History Museum, Budapest.

Hackman, W. (1980) A check list of the Finnish Diptera II. Cyclorrhapha. Notulae entomologicae, 60, 117-162.

Hironaga, T. \& Suwa, M. (2005) Notes on the genus Norellisoma in Japan, with description of a new species (Diptera, Scathophagidae). Studia dipterologica, 12, 199-208.

Jong, H. de (2002) Family Scathophagidae, pp. 334-337. In: Beuk, P.L.T. (ed.), Checklist of the Diptera of the Netherlands. KNNV Uitgeverij, Utrecht.

Jong, H. de (2004) Scathophagidae. In: Pape, T. (ed.), Diptera Brachycera. Fauna Europaea version 1.1, http:// www.faunaeur.org.

Karpa, A. (2008) Catalogue of Latvian flies (Diptera: Brachycera). Latvijas Entomologs, 46, 4-43.

Merz, B. \& Bächli, G. (1998) Scathophagidae. In: Merz, B., Bächli, G., Haenni, J.-P. \& Gonseth, Y. (eds.), Diptera - Checklist. Fauna helvetica, 1, 311-312.

Michelsen, V. \& Báez, M. (2002) Scathophagidae. In: Carles-Tolrá Hjorth-Andersen, M. (ed.), Catálogo de los Diptera de España, Portugal y Andorra (Insecta). Monografías S.E.A., 8, 222-223.

Nelson, J.M. \& Greve, L. (2002) New species of dung flies (Diptera, Scathophagidae) from Norway with a checklist of the Norwegian Scathophagidae. Norwegian Journal of Entomology, 49, 41-47.

Nelson, J.M. \& Šifner, F. (2000) A redescription of Norellisoma flavicorne (Meigen, 1826) (Dipt., Scathophagidae), with an account of its biology and notes on other members of the genus. Entomologist's Monthly Magazine, 136, 31-35.

Ozerov, A.L. (2007) On Scathophagidae species (Insecta: Diptera), described by F. Hendel from materials of the Swedish Kamchatka Expedition 1920-1922. Far Eastern Entomologist, 174, 5-8.

Ozerov, A.L. (2009) On the Palaearctic fauna of Norellisoma Wahlgren, 1917 (Diptera: Scathophagidae). Russian 
Entomological Journal, 18, 229-234.

Papp, L. (2001) Scathophagidae, pp. 381-385. In: Papp, L. (ed.), Checklist of the Diptera of Hungary. Hungarian Natural History Museum, Budapest.

Petersen, F.T. (2001) Scathophagidae. In: Petersen, F.T. \& Meier, R. (eds.), A preliminary list of the Diptera of Denmark. Steenstrupia, 26, 216-217.

Püchel, F. (1999): Scathophagidae. In: Schumann, H., Bährmann, R. \& Stark, A. (eds.), Checkliste der Dipteren Deutschlands. Studia dipterologica, Supplement, 2, 186-187.

Šifner, F. (2003) The family Scathophagidae (Diptera) of the Czech and Slovak Republics (with notes on selected Palaearctic taxa). Acta musei nationalis pragae, (B) 59, 1-90.

Šifner, F. (2008) A catalogue of the Scathophagidae (Diptera) of the Palaearctic Region, with notes on their taxonomy and faunistics. Acta entomologica musei nationalis pragae, 48, 111-196.

Vockeroth, J.R. (1965) Subfamily Scatophaginae, pp. 826-842. In: Stone, A., Sabrosky, C.W., Wirth, W.W., Foote, R.H. \& Coulson, J.R. (eds.), A catalog of the Diptera of America north of Mexico. United States Department of Agriculture. Agriculture Handbook 276. Washington, D.C. 